\title{
Effectiveness of Recapitulation of Stages of Labor Model for Learning Ability for BSc Nursing Students in Selected Colleges at Puducherry, India
}

\author{
V Poongodi ${ }^{1}, \mathrm{~K}_{\text {Renuka }}{ }^{2}, \mathrm{M}$ Annie Annal ${ }^{3}, \mathrm{R}$ Umamaheswari $^{4}, \mathrm{G}$ Nivetha $^{5}$
}

\begin{abstract}
During the physiological process of labor, from the uterus the fetus, membranes, umbilical cord, and placenta are expelled out. Background: The successful practice of tracking the learning activities based on the research literature is the fundamental component of high quality education.

Aim: To evaluate the effectiveness of the recapitulation of stages of labor (ROSOL) model on learning ability of final-year BSc nursing students. Materials and methods: The research approach was quantitative and one-group pretest-posttest preexperimental research design. A total of 90 students from BSc nursing final year, Kasturba Gandhi Nursing College, Puducherry, was selected by the purposive sampling technique. The pretest level of knowledge was assessed by a structured knowledge questionnaire and the ROSOL model was issued to the students. After 7 days, the posttest level of knowledge was assessed by using same structured knowledge questionnaires. Descriptive and inferential statistics like frequency, percentage, mean, standard deviation, and the Wilcoxon signed-rank test were used for analyzing the data.

Results: In pretest, 40 (44.4\%) had inadequate knowledge, 48 (53.3\%) had moderately adequate knowledge, and 2 (2.2\%) had adequate knowledge. In posttest, 1 had inadequate and moderately adequate knowledge and 90 (100\%) had adequate knowledge. The mean value was 9.81 and 17.68 during pre- and posttest, respectively. The median value was 10 and 18 during pre- and posttest, respectively. The obtained Wilcoxon signed-rank test value was 8.265 . The improvement of knowledge was assessed using the paired $t$-test; it was found statistically significant at $p<0.001$ level.

Conclusion: The ROSOL model was effective in improving the learning ability among final-year BSc nursing students.

Keywords: Effectiveness, Labor, Learning ability, ROSOL model.

Pondicherry Journal of Nursing (2020): 10.5005/jp-journals-10084-12146
\end{abstract}

\section{INTRODUCTION}

During the physiological process of labor, from the uterus the fetus, membranes, umbilical cord, and placenta are expelled out. $^{1-7}$ Ending of pregnancy means where one or more babies leaves a woman's uterus by passing through the vagina or by cesarean section, which is called as labor and delivery or childbirth. ${ }^{8-10}$ Globally, 135 million births were found in $2015 .{ }^{11,12}$ In that babies born before 37 weeks of gestation were about 15 million, after 42 weeks were about between $3 \%$ and $12 \%$. The majority of the deliveries occur in hospitals in the developed world and most of the births take place at home with the support of a traditional birth attendant in the developing countries. ${ }^{13-15}$

Vaginal delivery is the most common way of childbirth. Four stages are involved in this method. They are the shortening and opening of the cervix, descent and birth of the baby, placental delivery, and first 2 hours observation after delivery. About 12-19 hours for the first stage, 20 minutes to 2 hours for the second stage, and 5-30 minutes for the third stage. ${ }^{16-18}$ Abdominal cramps or back pains that last around half a minute occur every 10-30 minutes during the first stage. The pains become stronger and closer together over time. Pushing with contractions may occur during the second stage. Delayed clamping of the umbilical cord is generally recommended during the third stage. Relaxation techniques, opioids, and spinal blocks like a number of methods can help to reduce the pain during labor. ${ }^{19,20}$
${ }^{1,3-5}$ Department of Obstetrics and Gynecological Nursing, Kasturba Gandhi Nursing College, Puducherry, India

${ }^{2}$ Department of Medical Surgical Nursing, Kasturba Gandhi Nursing College, Puducherry, India

Corresponding Author: V Poongodi, Department of Obstetrics and Gynecological Nursing, Kasturba Gandhi Nursing College, Puducherry, India, Phone: +91 9585340354, e-mail: poongodiv@kgnc.ac.in

How to cite this article: Poongodi V, Renuka K, Annie Annal M, Umamaheswari R, Nivetha G. Effectiveness of Recapitulation of Stages of Labor Model for Learning Ability for BSc Nursing Students in Selected Colleges at Puducherry, India. Pon J Nurs 2020;13(1):4-6.

Source of support: Nil

Conflict of interest: None

Learning outcomes are clear to the students as a learners and the main intention are expected to achieve as a result of having a successful completion of the course. It describes the application of knowledge and skills, a person has acquired and able to demonstrate as a result of learning outcomes. ${ }^{21}$ An essential component of high-quality education is the body of the educational research literature, which has come to be known as the effective practice of monitoring the learning activities. The major factor differentiating effective college and teachers from ineffective ones is through careful monitoring of student progress.

(c) The Author(s). 2020 Open Access This article is distributed under the terms of the Creative Commons Attribution 4.0 International License (https://creativecommons. org/licenses/by-nc/4.0/), which permits unrestricted use, distribution, and non-commercial reproduction in any medium, provided you give appropriate credit to the original author(s) and the source, provide a link to the Creative Commons license, and indicate if changes were made. The Creative Commons Public Domain Dedication waiver (http://creativecommons.org/publicdomain/zero/1.0/) applies to the data made available in this article, unless otherwise stated. 
Determine and identified the different instructional practices and monitoring the students progress as a strong predictor of students achievement. $^{22}$ In obstetrics and gynecology, knowing stages of labor is very important both in academics and practice. Students find difficult to understand the detailed contents of four stages of labor. The recapitulation of stages of labor (ROSOL) model explains all four stages of labor definition, duration, signs and symptoms, and physiological changes and management in a sequential order. This model is created for the benefits of easy learning and understanding of the parturition process for the students and healthcare professionals. It is most needed one for the students for easy recall and remembrance.

In 21st century, improving the education quality and quality assurance have become the most distinctive themes of higher education reform. ${ }^{17,21,23}$ The most direct evidence to higher education quality of the students is the learning outcome and should be an indispensable element and the starting point of education evaluation; in most countries, evaluations have not regarded students as the most important target in their systems. ${ }^{6,14}$

\section{Objectives}

- To assess the level of knowledge on stages of labor among BSC nursing students.

- To evaluate the effectiveness of the ROSOL model on learning ability on stages of labor among BSc nursing students.

- To associate the level of knowledge on stages of labor among BSc nursing students with selected demographic variables.

\section{Hypotheses}

$\mathrm{H}_{1}$ : Learning ability among BSc nursing students varies pre and post implementing the ROSOL model.

$\mathrm{H}_{2}$ : There was a significant association between the level of learning ability and their selected demographic variables.

\section{Materials and Methods}

Quantitative research approach and one-group pretest-posttest preexperimental research design were used. A total of 90 students from BSc nursing final year, Kasturba Gandhi Nursing College, Puducherry, were selected based on the inclusion and exclusion criteria by the purposive sampling technique. The researcher obtained formal permission and informed consent from the study participants. The purposes of the study were explained to all the samples. The demographic variables were collected using the structured questionnaire. The pretest level of knowledge was assessed by the structured knowledge questionnaire and the ROSOL model was issued to the students. The ROSOL model explains all four stages of labor definition, duration, signs and symptoms, and physiological changes and management in a sequential order. After 7 days, the posttest level of knowledge was assessed by using same structured knowledge questionnaires. Descriptive and inferential statistics like frequency, percentage, mean, standard deviation, and the Wilcoxon signed-rank test were used for analyzing the data.

\section{Results}

Majority of the samples $(52,57.8 \%)$ belong to the age group of 21 years; $75(83.3 \%)$ of them were female, $63(70 \%)$ were from nuclear family, 80 (88.9\%) were hinds, 46 (51\%) were from urban area, and majority of the samples $(38,42.22 \%)$ were getting the information from health professionals.

In pretest, out of 90 samples, 40 (44.4\%) of BSc nursing students had inadequate knowledge, 48 (53.3\%) had moderately adequate knowledge, and $2(2.2 \%)$ had adequate knowledge on stages of labor. In posttest, 1 had inadequate and moderately adequate knowledge and 90 (100\%) had adequate knowledge on stages of labor. This shows the effectiveness of the ROSOL model for increasing learning ability for BSc nursing students (Fig. 1).

Mean values were 9.81 and 17.68 during pre- and posttest, respectively. The median values were 10 and 18 during pre- and posttest, respectively. The obtained Wilcoxon signed-rank test value was 8.265 . The improvement of knowledge was assessed using the paired $t$-test; it was found statistically significant at $p<$ 0.001 level. It indicates that effectiveness of the ROSOL model for increasing learning ability for BSc nursing Students. Hence, the stated hypothesis $\mathrm{H}_{1}$ was accepted (Fig. 2).

In association, by using Mann-Whitney and Kruskal-Wallis tests, it was evidenced that there was no significant association between the demographic variables like age, gender, type of family, religion, area of living, and source of health information with their level of knowledge at $p$ value $<0.001$ level. Hence, the stated hypothesis $\mathrm{H}_{2}$ was rejected.

\section{Implications}

The finding of the research study was pointed out that the ROSOL model for learning ability for BSc nursing students. The student nurses have a very important role in learning stages of labor. This can be facilitated by encourage the students to utilize this model, which is very useful learning material to improve their knowledge. This model is presented in the form of single frame, is easily understandable, and used in both education and clinical settings. It mainly helps the students to learn the normal labor in a simple way and is time-saving; it is most needed one for the students for easy recall and remembrance; it is different from other flow charts; and this is only model that includes all the four stages of labor information in an easily understandable one.

\section{Limitation}

It is useful for obstetrical practice only.

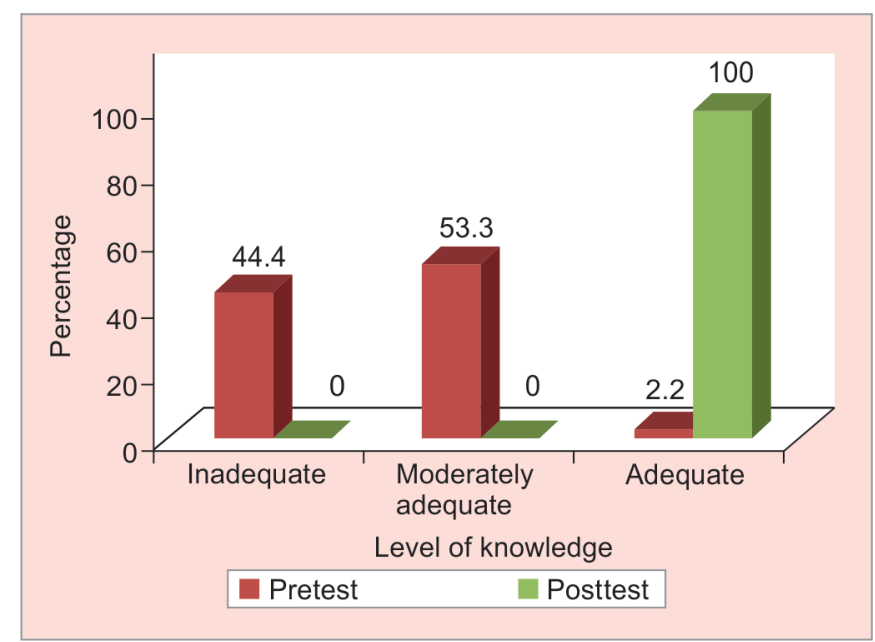

Fig. 1: Distribution of level of knowledge among BSc nursing students during pretest and posttest 


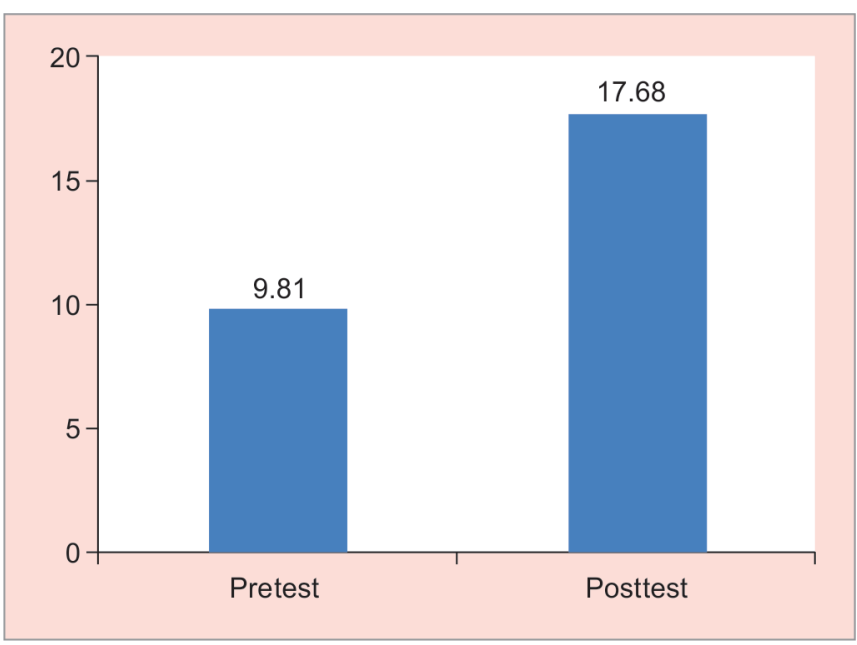

Fig. 2: Comparison of pretest and posttest mean levels of knowledge among BSc nursing students

\section{Recommendations}

- The study can be replicated with a large sample for better generalization.

- More studies can be conducted on improving students' learning abilities using different modalities to establish a rightful place to improve the knowledge.

- Studies can be done to assess the knowledge, attitude, and practice of students with this learning model.

- Comparison can be done to evaluate the effectiveness of other interventions.

\section{Conclusion}

The main conclusion of this study was the ROSOL model for learning ability of BSc nursing students.

\section{References}

1. Lunze K, Bloom DE, Jamison DT, Hamer DH. The global burden of neonatal hypothermia: systematic review of a major challenge for newborn survival. BMC Med 2013;11(1):24. DOI: 10.1186/1741-701511-24.

2. World Health Organisation. Education material for teachers of midwifery: midwifery education modules (PDF). 2nd ed., Geneva [Switzerland]: World Health Organisation; 2008. p. 3.

3. Memon HU, Handa VL. Vaginal childbirth and pelvic floor disorders. Women's Health 2013;9(3):265-277. quiz 276-277 10.2217/WHE.13.17.
4. Martin RJ, Fanaroff AA, Walsh MC. Fanaroff and Martin's NeonatalPerinatal Medicine: Diseases of the Fetus and Infant. Elsevier Health Sciences, p. 116.

5. Martin E. Concise Colour Medical I.p.Dictionary. Oxford University Press; 2015. p. 375.

6. Dutta DC. Text Book of Obstetrics. 6th ed., Calcutta: New Central Book Agency; 2004. pp. 115-116.

7. Fraser, Cooper. Myles Text Book for Midwives. 14th ed., London: Churchill Livingstone; 2005. pp. 246-248.

8. "The World Factbook". www.cia.gov. July 11, 2016. Archived from the original on 16 November 2016. Retrieved 30 July 2016.

9. Olsen O, Clausen JA. Planned hospital birth versus planned home birth. Cochrane Database Syst Rev 2012(9):CD000352. DOI: 10.1002/14651858.CD000352.pub2.

10. Pillitteri A. Maternal and Child Health Nursing. 5th ed., Philadelphia: Lippincott Williams and Wilkins Publication; 2007.

11. Preterm birth Fact sheet No 363". WHO. November 2015. Archived from the original on 7 March 2015. Retrieved 30 July 2016.

12. de Fossard E, Bailey M. Communication for Behavior Change: Volume III: Using Entertainment-Education for Distance Education. India: SAGE Publications; 2016.

13. Buck GM, Platt RW. Reproductive and Perinatal Epidemiology. Oxford: Oxford University Press; 2011. p. 163.

14. "Birth". The Columbia Electronic Encyclopedia (6 ed.). Columbia University Press. 2016. Archived from the original on 2016-03-06. Retrieved 2016-07-30 - via Encyclopedia.com.

15. International Confederation of Midwives; International Federation of Gynaecologists Obstetricians. Joint statement: management of the third stage of labour to prevent post-partum haemorrhage. J Midwifery Womens Health 2004;49(1):76-77. DOI: 10.1111/j.15422011.2004.tb04420.x.

16. Co-Operation, Organisation for Economic Development. Doing Better for Children. Paris: OECD; 2009. p. 105.

17. "Pregnancy Labor and Birth". Women's Health. September 27, 2010. Archived from the original on 28 July 2016. Retrieved 31 July 2016.

18. National Institute for Health and Care Excellence. "Intrapartum care: care of healthy women and their babies during childbirth". National Institute for Health and Care Excellence. Archived from the original on 18 February 2015. Retrieved 11 February 2015.

19. McDonald SJ, Middleton P, Dowswell T, Morris PS. Effect of timing of umbilical cord clamping of term infants on maternal and neonatal outcomes. Cochrane Database Syst Rev 2013;7(7):CD004074. DOI: 10.1002/14651858.CD004074.pub3.

20. Jangsten $E$, Mattsson LÅ, Lyckestam I, Hellström AL, et al. A comparison of active management and expectant management of the third stage of labour: a Swedish randomised controlled trial. BJOG 2011;118(3):362-369. DOI: 10.1111/j.1471-0528.2010.02800.x.

21. Rajeshwari R, Vijayalakshmi. Child birth baboon or a bane. J Nightingale Nurs Times 2013;7(9):4-6.

22. Geetha CR. Pregnancy and childbirth. J Midwifery Nurs 2013(3):15.

23. Satin AJ, (July 1, 2013). "Latent phase of labor". UpToDate. Wolters Kluwer. Archived from the original on March 3, 2016. 